\title{
Avaliação integrada do estado de conservação do edifício Adriano Marchini, IPT, São Paulo
}

Mírian Cruxên Barros de Oliveira* e Gilberto de Ranieri Cavani**

Instituto de Pesquisas Tecnológicas do Estado de São Paulo

Av. Prof. Almeida Prado, 532 - Cidade Universitária

CEP 05508-901 - São Paulo, SP. Telefone: +(11) 3767-4367 / 4124

www.ipt.br

\section{Resumo}

O IPT participa da Rede "Processos e técnicas de avaliação e intervenção em bens culturais - RECICOR", financiada pelo Conselho Nacional de Desenvolvimento Científico e Tecnológico - CNPq, por meio do projeto "Rede de Apoio Tecnológico para Restauração e Conservação de Patrimônio Histórico-Cultural - RETECOP”.

A edificação estudada foi o Edifício Adriano Marchini, pertencente ao IPT e localizado na Cidade Universitária, em São Paulo, capital. Trata-se de um prédio importante do ponto de vista histórico-cultural e que representa uma fase característica da construção civil e da arquitetura paulistana do final da primeira metade do Século 20, sendo também o primeiro prédio administrativo construído na Cidade Universitária/Universidade de São Paulo. Esse trabalho contempla as áreas de atuação do Instituto em patrimônios históricos, abrangendo a edificação. Além da caracterização dos materiais constituintes são abordados aspectos relacionados à segurança estrutural da edificação, sua segurança ao fogo, à durabilidade e à estanqueidade das suas vedações. A elaboração de um procedimento sistemático para avaliação integrada do estado de conservação da edificação selecionada contempla os seguintes aspectos:

- caracterização histórica do prédio;

- caracterização e avaliação dos sistemas construtivos, elementos, componentes e instalações, incluindo os diversos materiais utilizados (madeiras, argamassas, rochas e metais);

- avaliação da estabilidade estrutural da edificação;

- avaliação de condições de habitabilidade e salubridade das edificações;

- diagnóstico das principais manifestações patológicas identificadas;

- recomendação de medidas corretivas, curativas e preventivas. 


\section{Introdução}

Por meio de projeto financiado pelo CNPq (Oliveira, 2004), o IPT formou a Rede de Apoio Tecnológico para a Restauração e Conservação do Patrimônio Histórico RETECOP, destinada a dar apoio à comunidade de restauradores atuantes nos diversos programas de conservação da memória histórica e cultural do País.

Esse projeto, desenvolvido de 2002 a 2004, visou adequar e coordenar as atividades do conjunto de laboratórios e equipes técnicas do IPT, com o objetivo precípuo de oferecer uma abordagem tecnológica e científica, com caráter multidisciplinar e inovador, para a solução de problemas em dois segmentos: edifícios históricos e acervo em papel. Para tanto, buscou-se a consolidação do conhecimento acumulado, atualmente disperso no Instituto, bem como a ampliação da capacitação dos laboratórios e integração das diversas áreas afins do IPT: Construção Civil, Madeira, Papel, Metalurgia, Geologia e Química, visando o desenvolvimento de uma sistemática de atuação abrangente e efetiva. Esta ampliação da capacitação concentrou-se no aprimoramento das técnicas já disponíveis, adequando-as às necessidades da preservação do patrimônio histórico, mas também considerou a introdução de novas técnicas não destrutivas, que permitem a avaliação prévia das obras, reduzindo ao mínimo a intervenção para coleta de amostras para caracterização mais detalhada.

Além da caracterização dos materiais constituintes, foram abordados aspectos relacionados à segurança estrutural da edificação, sua segurança ao fogo, à durabilidade e à estanqueidade das suas vedações. A edificação escolhida foi o edifício Adriano Marchini, localizada no campus do próprio instituto.

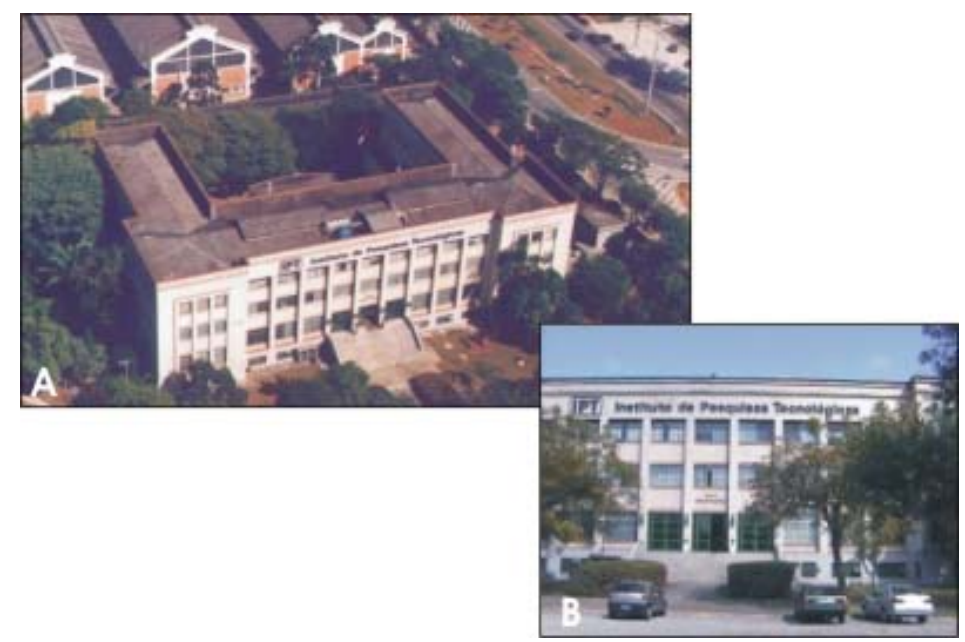

FIGURA 1 - (A) Fotografia aérea do Edifício Adriano Marchinni (Fotografia: Arquivo IPT). (B) Vista geral da fachada principal. Bom estado de conservação. (Fotografia: Gilberto R. Cavani) 
As razões para a escolha desse prédio foram as seguintes:

- trata-se do primeiro prédio administrativo do Campus Universitário do Município de São Paulo;

- é uma edificação construída entre 1947- 1954, época da qual datam várias edificações da cidade de São Paulo;

- sua história está intimamente ligada à história da tecnologia paulista;

- faz parte do patrimônio do Instituto, facilitando sobremaneira o seu estudo.

\section{Objetivos}

O objetivo desse trabalho é apresentar uma proposta de procedimento sistemático para a avaliação das condições de edificações históricas por meio da atuação multidisciplinar e proposição de eventuais medidas corretivas ou até de caráter preventivo, consolidando-o via sua aplicação no exemplo real de uma edificação com necessidade de intervenção preventiva e/ou restauradora.

\section{Métodos de trabalho}

Os trabalhos executados pelas equipes multidisciplinares do IPT iniciaram em 2002 e se prolongaram até agosto de 2004. Foram realizadas várias reuniões entre os pesquisadores, para que houvesse certa uniformidade de métodos, respeitando as diferenças entre cada uma das áreas do conhecimento. Ao final dos trabalhos cada equipe elaborou um relatório contendo, em linhas gerais, as informações obtidas durante a inspeção, métodos de caracterização dos materiais examinados, recomendações de medidas para reparo das anomalias existentes e outras irregularidades, visando à conservação da edificação.

A seguir são listadas as etapas de trabalho desenvolvidas por cada área do conhecimento. 


\subsection{Pesquisa histórica}

- Levantamento bibliográfico (acervo IPT e outros)

- Entrevista com funcionários antigos e atuais do IPT

- Análise, seleção e organização dos dados levantados

\subsection{Estrutura de concreto e alvenaria}

- Verificação da documentação existente referente à construção de fundações, estrutura e alvenarias do prédio;

- Inspeção da edificação para identificar as alterações feitas em função de novas ocupações e as anomalias existentes;

- Identificação das situações de risco aos usuários;

- Caracterização do concreto utilizado quanto à uniformidade e o estado/avanço da frente de carbonatação.

\subsection{Estruturas e elementos em madeira}

- Biodeterioração da madeira em edificações históricas;

- Inspeção detalhada quanto à sanidade biológica;

- Inspeção do madeiramento da cobertura e análise estrutural;

- Análise de medidas corretivas, curativas e/ou preventivas;

- Controle de cupins-subterrâneos com utilização de iscas;

- Avaliação do estado de sanidade biológica de peças estruturais de madeira por meio de ensaio não-destrutivo; 
- Obtenção de amostras biodeterioradas e sadias;

- Ensaios laboratoriais.

\subsection{Revestimento em placas de rocha}

- Reconhecimento da área de trabalho;

- Levantamento dos dados históricos do revestimento;

- Identificação do material utilizado no revestimento;

- Inspeção visual com registro fotográfico;

- Identificação das degradações e medição de grau de lustro, desgaste abrasivo e outros;

- Avaliação do estado de conservação.

\subsection{Estruturas e elementos em metais}

- Inspeção visual com registro fotográfico;

- Determinação da espessura da camada de zinco dos elementos galvanizados e da camada de tinta aplicada;

- Avaliação da aderência da camada de tinta nos equipamentos e componentes pintados;

- Elaboração de especificação para a recuperação dos equipamentos e componentes inspecionados, contendo:

métodos de recuperação para cada um dos equipamentos (preparo de superfície, solda, aplicação de revestimentos metálicos, etc); 
especificação dos esquemas de pintura a serem utilizados;

especificação das tintas a serem utilizadas e seus requisitos mínimos.

\subsection{Revestimento em argamassa}

- Análise preliminar do estado do revestimento;

- Coleta de amostras;

- Inspeção das anomalias;

- Ensaios de caracterização do revestimento;

- Avaliação dos resultados dos ensaios e elaboração de diretrizes para formulação de argamassas de restauro.

\subsection{Conforto ambiental}

- Verificação da documentação existente;

- Inspeção in loco.

\subsection{Segurança ao fogo}

- Projeto executivo de Sistema de Detecção e Alarme de Incêndio;

- Projeto executivo de Sistema de lluminação de Emergência;

- Projeto executivo de Sistema de Extintores, Hidrantes e Mangotinhos;

- Projeto executivo de Sistema de Sinalização de Emergência.

\subsection{Integração dos relatórios parciais}

A integração dos trabalhos realizados em cada área redundou num relatório geral, contendo conclusões gerais, além de recomendações de medidas corretivas, curativas e preventivas. 


\section{Principais resultados obtidos}

O principal avanço obtido nesse projeto foi a efetiva participação de equipes multidisciplinares do IPT, que atuaram de forma integrada, visando um objetivo comum.

\subsection{Apresentação e breve histórico da edificação}

Os primeiros prédios do IPT, construídos na Cidade Universitária, eram destinados às atividades da Seção de Metalurgia, daí o nome Pavilhões da Metalurgia.

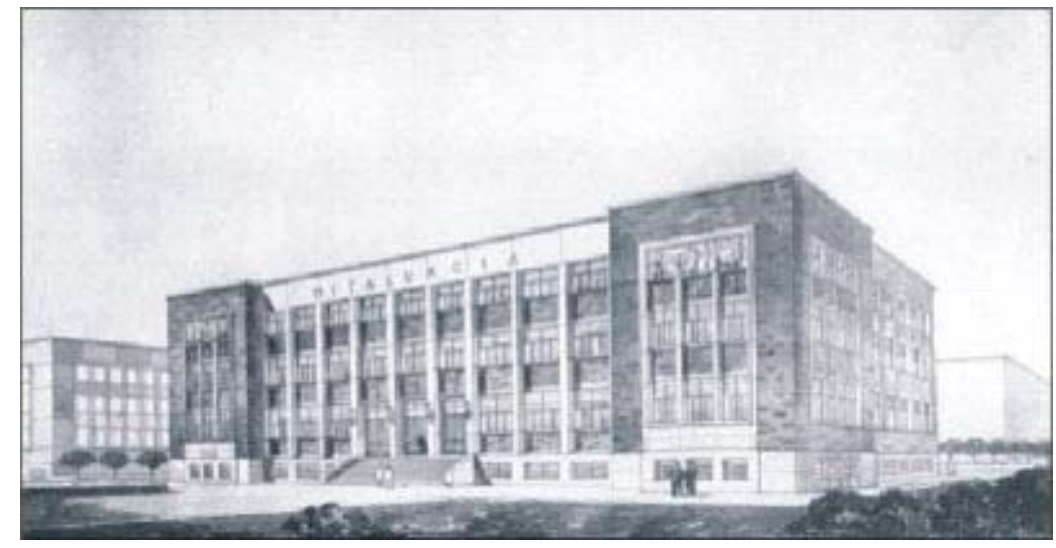

FIGURA 2 - Aspecto do Edifício de Administração e Laboratórios da Divisão de Metalurgia (Desenho: Arquivo IPT)

Em 1949 decidiu-se redimensionar a utilização de uma das construções (edifício de metalurgia), designando-o como Edifício Sede, comportando as seguintes seções: Administração, Aglomerantes e Concretos, Ensaios Mecânicos, Ensaios de Metais, Solos e Fundações, Estrutura, Metalurgia Física, Biblioteca e Especificação. Com uma área total construída de aproximadamente $7.300 \mathrm{~m}^{2}$, com 4 pavimentos.

O Relatório das obras do IPT na Cidade Universitária, apresentado pelo engenheiro - arquiteto José Maria da Silva Neves em 1946, aponta que a Cidade Universitária ainda não possuía um projeto arquitetônico definitivo e por isso optou-se por exprimir nos edifícios funcionalidade, elegância de linhas e certa nobreza, uma vez que os mesmos tinham caráter semi-industrial, mas, estavam localizados num conjunto universitário.

A construção do prédio principal finalizou-se em 1953 e, no ano de 1965, passa a se chamar "Edifício Adriano Marchini", em homenagem a esse pesquisador e 
engenheiro que se dedicou com afinco não apenas a essa obra, mas também para a ampliação e desenvolvimento geral do IPT.

\subsection{Descrição da edificação}

A edificação é composta por três blocos separados por juntas de dilatação, sendo denominados de ala direita, ala esquerda e ala central.

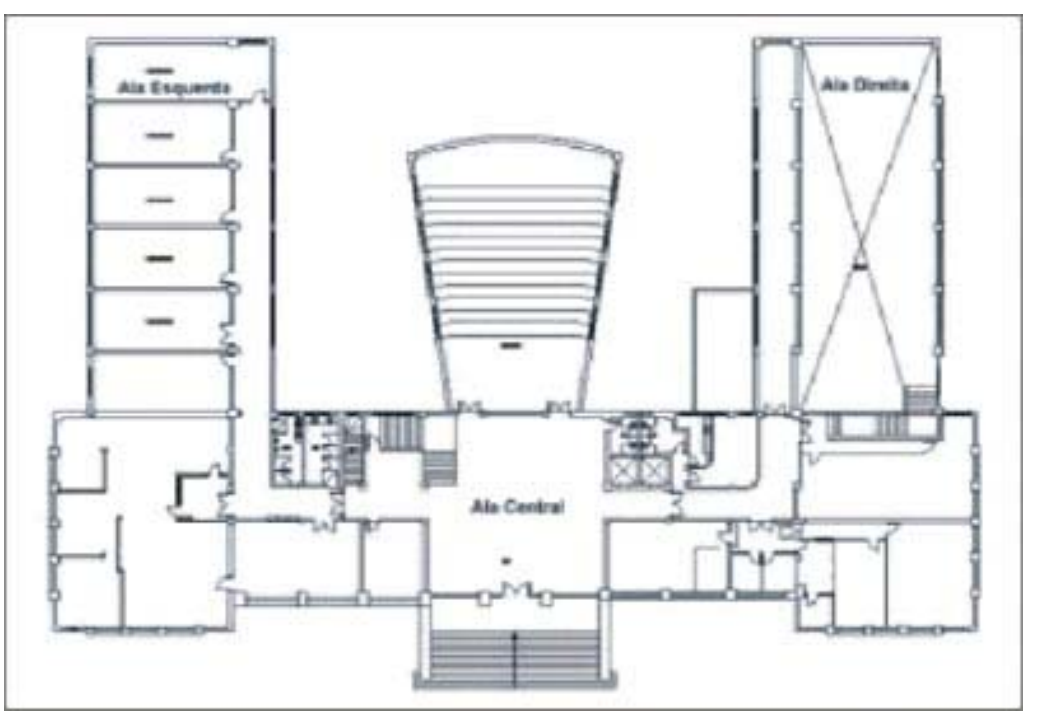

FIGURA 3 - Planta do 10 pavimento do edifício Adriano Marchini (Desenho: Arquivo IPT)

As alas direita e esquerda são constituídas por quatro pavimentos, incluindo o térreo, e cobertura, onde se encontra a Casa de Máquinas. A ala central é constituída de quatro pavimentos, no trecho disposto transversalmente às demais e dois pavimentos, incluindo o térreo, no trecho disposto paralelamente a elas, onde se encontra o auditório.

Quanto aos sistemas construtivos, materiais e elementos utilizados ressalta-se que:

- na fachada, a estrutura de concreto e a alvenaria são revestidas em sua totalidade por revestimento de argamassa (Figura1B);

- a cobertura da edificação é composta de telhas de fibrocimento apoiadas em estrutura de madeira;

- no interior da edificação, a estrutura de concreto encontra-se em grande parte revestida por argamassa, com exceção das lajes; 
- o forro do terceiro pavimento da ala esquerda é constituído por placas de aglomerado de madeira, provavelmente o sistema original, fixadas em estrutura de madeira;

- o forro do terceiro pavimento da ala central foi trocado por placas de gesso suspensas por fios de arame fixados na estrutura de madeira;

- o forro do terceiro pavimento da ala direita foi trocado por sistema de forro de gesso fixados na estrutura de madeira;

- não existe sistema de forro nos demais trechos dos blocos onde as lajes de concreto receberam exclusivamente pintura;

- a distribuição do interior é constituída de alvenaria de tijolos, revestida com argamassa, ou divisórias leves de madeira e/ou gesso;

- as portas são na sua maioria em madeira e na minoria metálicas;

- as esquadrias de janelas são na sua maioria metálicas e na minoria em madeira.

\subsection{Caracterização e avaliação dos diversos materiais, elementos e sistemas construtivos utilizados}

\subsubsection{Estrutura de concreto e alvenaria / Características do concreto}

O trabalho completo referente à estrutura de concreto e alvenaria encontra-se em INSTITUTO DE PESQUISAS TECNOLÓGICAS (2004a).

A inspeção visual da estrutura de concreto e alvenaria da edificação foi realizada por engenheiros civis, visando verificar as condições em que se encontra a edificação, levantamento das anomalias existentes nos elementos estruturais em concreto e alvenarias, de modo a identificar as causas e apresentar recomendações de medidas para a conservação da edificação. A edificação foi vistoriada no seu entorno (calçadas e fachadas); cobertura e sótão (acesso pelo último pavimento) e no interior (térreo, primeiro, segundo e terceiro pavimentos). 
Complementou-se a inspeção com o levantamento das informações quanto às alterações existentes durante os cinqüenta anos de utilização do edifício, necessárias para sua adequação às novas utilizações; avaliação da uniformidade de elementos de concreto pela determinação de sua dureza superficial, utilizando esclerômetro de reflexão em vigas e pilares da estrutura e verificação da profundidade/avanço da frente de carbonatação por aspersão de indicador químico de $\mathrm{pH}$, fenolftaleína.

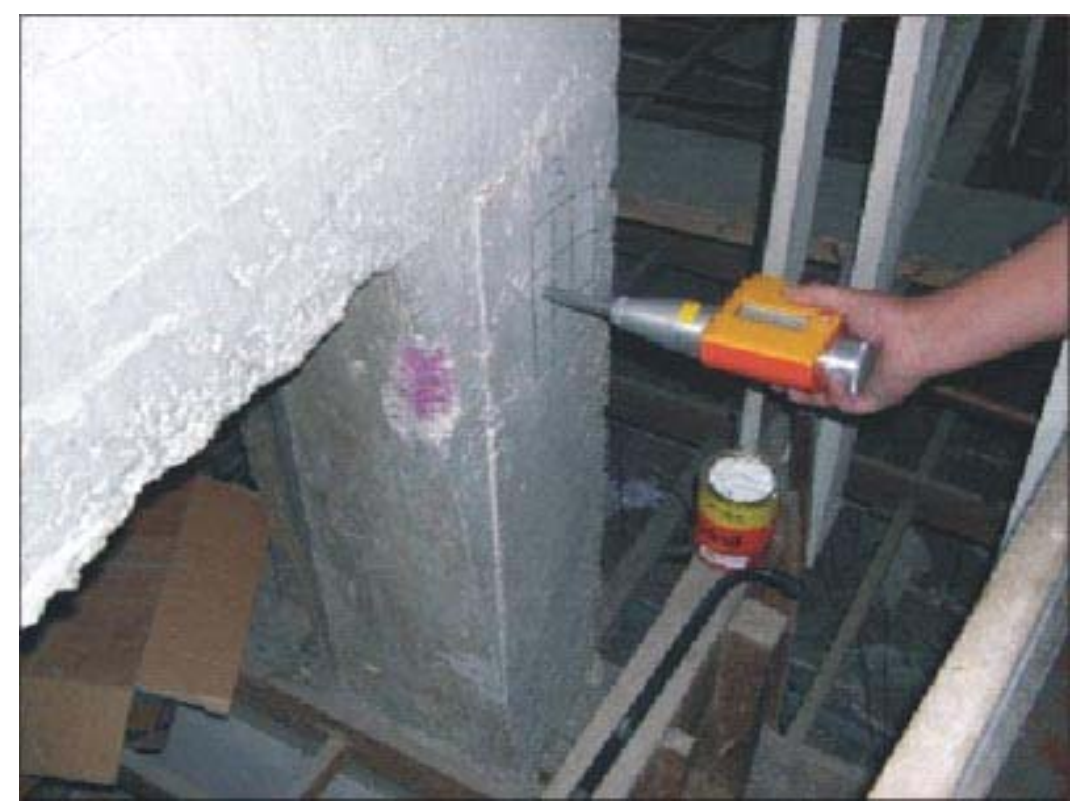

FIGURA 4 - Esclerometria em pilar de apoio da caixa d'água localizada na ala central do Edifício Adriano Marchini e verificação da alcalinidade da camada de concreto por indicador químico. (Fotografia: Claudia B. do Nascimento)

A verificação da dureza superficial indicou uniformidade nos elementos em concreto, apresentando valores consideráveis (índice esclerométrico efetivo variando de 47 a 53). O avanço da frente de carbonatação é pequeno e a armadura encontra-se em região passivada, ou seja, com baixo risco de corrosão.

\subsubsection{Estruturas e elementos em madeira}

$\mathrm{O}$ trabalho completo referente à estrutura e elementos em madeira encontra-se em INSTITUTO DE PESQUISAS TECNOLÓGICAS (2004b).

$\mathrm{Na}$ área de madeiras, um grupo formado por engenheiros civis e agrônomos, biólogos e ecólogos realizou o diagnóstico dos problemas ocasionados pela biodeterioração da madeira avaliando, também, as diversas interferências realizadas ao longo do tempo no patrimônio e que podem ter ou não contribuído para aumentar o tempo de vida daquela edificação. As estruturas de cobertura do telhado principal 
foram inspecionadas a partir dos espaços situados entre forro e telhado. $\mathrm{O}$ acesso a elas deu-se por meio de escada situada no $3^{\circ}$ pavimento da edificação.

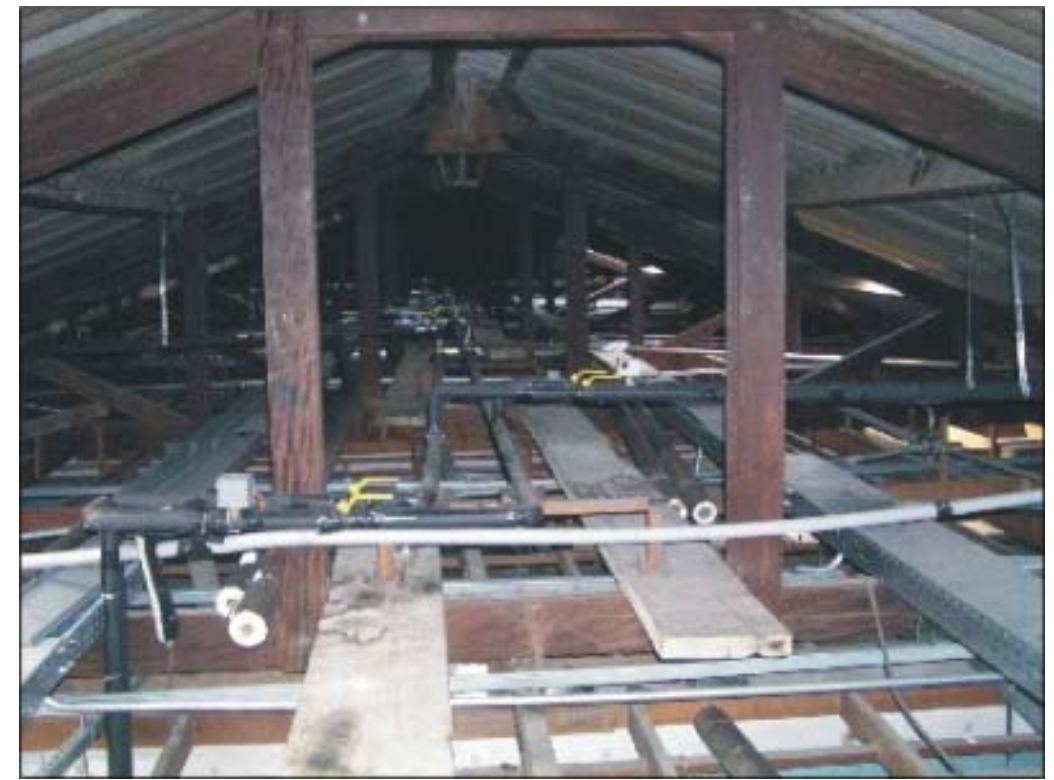

FIGURA 5 - Estrutura de madeira de apoio do telhado do Edifício Adriano Marchini. (Fotografia Claudia B. do Nascimento).

A inspeção da estrutura de cobertura do anfiteatro, localizado no segundo pavimento da edificação, foi parcial. O conjunto de tesouras e demais peças estruturais foi inspecionado visualmente através da abertura feita no forro.

Quanto à sanidade biológica, foram examinadas visualmente peças de madeira em contato com a alvenaria como: rodapés; assoalhos; batentes e guarnições de portas e janelas; lambris; caixas de distribuição elétrica. Também foram avaliadas as tesouras, vigas, caibros e demais peças de madeira das estruturas dos telhados e forros.

A identificação botânica das espécies de madeira empregadas nos componentes da edificação foi por meio do método macroscópico e microscópico de análise da madeira.

Com o objetivo de coletar, para a análise estrutural, dados de geometria e detalhes construtivos dos elementos em madeira, foi efetuado um levantamento em todas as peças de importância estrutural, observando-se as ligações, deformações dos nós e problemas pontuais de sobrecarga. 
O levantamento das características mecânicas e a avaliação de seu estado de sanidade biológica foram concomitantes.

\subsubsection{Ataque de organismos xilófagos}

Observou-se o ataque de cupins-subterrâneos nos dois primeiros pavimentos da edificação.

Exceto pela presença de pontos isolados de apodrecimento, ainda em estágio inicial, não foi observado ataque de fungos apodrecedores no madeiramento desta edificação.

\subsubsection{Análise Estrutural}

Os principais elementos estruturais considerados são as tesouras (T1 a T4), as diagonais dos encontros das águas e as terças. Os esforços mais críticos, para cada elemento estrutural foram utilizados para avaliar as condições de segurança. Segundo a especificação da norma, considera-se satisfeito o requisito de segurança quando o elemento analisado apresentar condição de segurança com valor inferior a 1. Analisando-se os componentes mais críticos da tesoura T1, verificam-se que as peças de madeira que formam os banzos superior e inferior, bem como a ligação de madeira (junção do banzo superior e inferior) e a ligação parafusada do banzo inferior, atendem aos requisitos de segurança. O mesmo ocorre com as tesouras, espigões e terças.

\subsubsection{Revestimento em placas de rochas}

O trabalho completo referente ao revestimento em placas de rochas encontra-se em INSTITUTO DE PESQUISAS TECNOLÓGICAS (2004c).

Esse trabalho apresenta o resultado do estudo diagnóstico do estado de conservação do mármore que reveste o piso do saguão ( $1^{\circ}$ pavimento) e degraus da escadaria, do saguão ao $3^{\circ}$ pavimento. $O$ mármore apresenta cor rosa a vermelho claro com faixas de cor verde.

O exame microscópico das seções delgadas indicou que a rocha é petrograficamente classificada de (clorita)-dolomita-calcita mármore. 
A análise mineralógica por difratometria de raios $X$ revelou que o tom verde de algumas bandas, observado macroscopicamente, deve-se à presença de clorita, e outros filossilicatos (sericita), aos quais se associam cristais de quartzo. As diferenças nas tonalidades avermelhadas - ora mais claras, ora mais escuras resultam de variações na granulação e no tipo de carbonato, sendo os tons mais escuros associados à predominância de dolomita, de granulação média a grossa, e os tons mais claros associados à predominância de calcita, de granulação fina.

Os ladrilhos são de mármore rosa-acinzentado, com bandas alternadas de cor verde-escuro ou vermelho-claro. A inspeção visual revelou que o mármore encontrase bastante desgastado pelo uso, mas, no geral, sem deteriorações muito graves, do ponto de vista funcional. São notáveis os sulcos e elevações relativos às diferenças de dureza dos minerais componentes das várias bandas.

Filetes de cor branca, ricos em quartzo, destacam-se do restante do material.

Um aspecto construtivo notável é a ausência de paginação. A disposição dos ladrilhos é muito irregular.

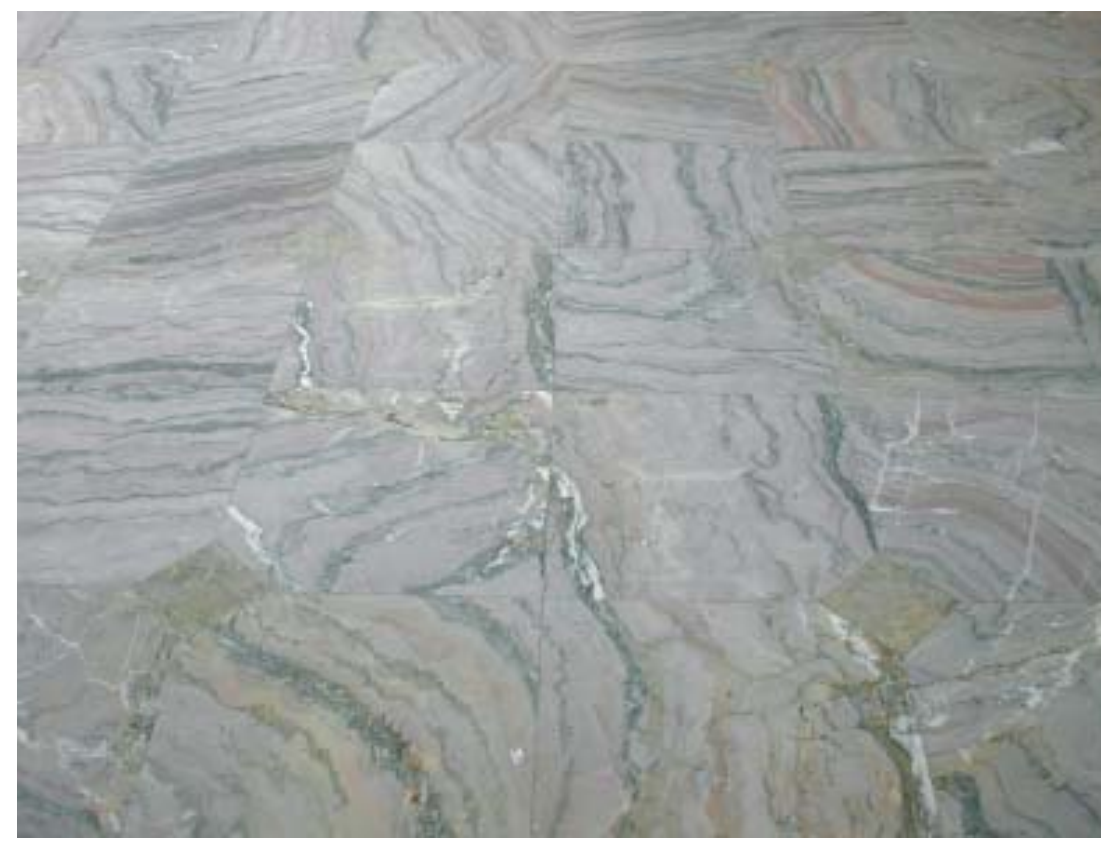

FIGURA 6 - Aspectos da disposição dos ladrilhos no saguão. (Fotografia Maria Heloisa B. O. Frascá). 
Em alguns locais (raros) há preocupação na continuidade da padronagem, mas, em geral é aleatória, sendo comuns intercalações de ladrilhos vermelhos entre os de cor rosa. Em área atrás da escala foram utilizados somente ladrilhos vermelhos.

Além do desgaste mencionado, modificação considerada natural para o tipo de material escolhido, foram observadas outras deteriorações, todas atribuíveis aos cerca de 50 anos de uso conjugados a prováveis irregularidades nas operações de limpeza e manutenção.

Foi atribuída a designação "padrão" aos ladrilhos que exibem somente desgaste e com base nisto foi realizada a inspeção de todos os ladrilhos do saguão de entrada do Ed. Adriano Marchini. As deteriorações foram identificadas como de dois tipos principais: presença de cavidades e/ou de amarelamento, frequentemente de ocorrência conjunta na mesma placa.

As escadas apresentam desgaste mais intenso, porém mais regular (sulcos praticamente ausentes), que o do piso do saguão, concentrado na região central e próxima às bordas dos degraus.

\subsubsection{Estruturas e elementos em metais}

$\mathrm{O}$ trabalho completo referente à estrutura e elementos em metais encontra-se em INSTITUTO DE PESQUISAS TECNOLÓGICAS (2004d).

Existe uma grande quantidade de elementos metálicos confeccionados em açocarbono pintado, tais como janelas, tubulações, suportes e braçadeiras, instalados no edifício Adriano Marchini. No caso de alguns destes elementos, notadamente os que estavam instalados na área externa do prédio, foi possível verificar a ocorrência de corrosão do aço-carbono, em áreas onde houve danificação da pintura.

Para os elementos metálicos confeccionados em aço-carbono zincado sem pintura, tais como tubulações, eletrodutos, chapas e capas protetoras, foi possível verificar que os elementos que estavam instalados na área interna apresentavam, de maneira geral, bom aspecto, sem sinais de corrosão. Vários elementos instalados na área externa do prédio apresentam corrosão do substrato. 
No caso dos elementos metálicos confeccionados em aço-carbono zincado pintado, tais como tubos, chapas, eletrodutos e guarda-corpos, foram observadas duas situações problemáticas: destacamento de pintura e corrosão do substrato. Nos casos onde foi verificada a corrosão do substrato, os elementos zincados encontravam-se na área externa do prédio.

Foi observada a presença de diversas manchas na porta de entrada principal do edifício Adriano Marchini.

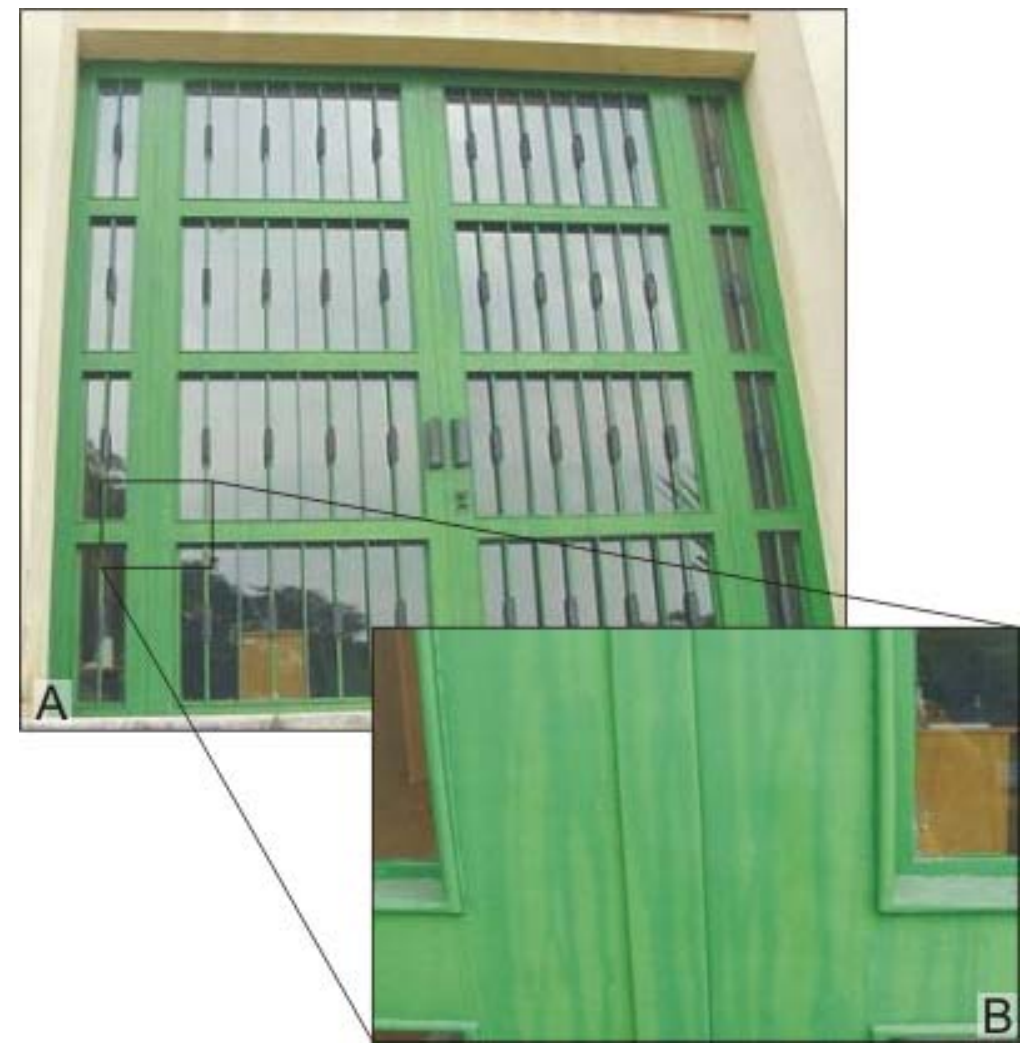

FIGURA 7 - (A) aspecto visual geral da porta de entrada do edifício. (B) aspecto visual da porta de entrada do edifício. Observa-se a presença de manchas (Fotografias: Sidney $O$. Pagotto Júnior).

Recomenda-se que toda a pintura seja lixada levemente, para a quebra do brilho. A seguir, deve-se limpar todo o pó, assim como qualquer outra sujidade presente, aplicando-se finalmente uma demão de tinta poliuretânica na cor desejada.

Os cabos de cobre fixados na fachada do edifício, utilizados para aterramento, estão manchando a fachada o prédio. É recomendável a aplicação de uma graxa condutora, de forma a evitar a corrosão deste cabo e eliminar o manchamento das paredes. 
Durante a inspeção verificou-se que os trincos e maçanetas das janelas, confeccionados em aço-carbono cromado, apresentavam desgaste acentuado do revestimento. Embora não tenham sido observados problemas de corrosão, do ponto de vista estético a peça está comprometida.

Durante a inspeção, verificou-se a presença de alguns elementos confeccionados em bronze, a saber: a maçaneta e os ornamentos presentes na porta de entrada do edifício.

No caso da maçaneta, verificou-se que a superfície da peça apresentava um aspecto não-uniforme, sendo possível notar vários pontos onde havia acúmulo de produtos de corrosão. Já os ornamentos apresentavam um aspecto escurecido, devido à formação de uma camada de produtos de corrosão escuros na sua superfície.

\subsubsection{Revestimentos em Argamassas}

O trabalho completo referente aos revestimentos em argamassa encontra-se em INSTITUTO DE PESQUISAS TECNOLÓGICAS (2005).

A avaliação de revestimentos com vistas à caracterização da argamassa e à identificação das causas das anomalias envolveram a participação de engenheiros civis, químicos, geólogos e bióloga.

Segundo consta no relatório de obras, no projeto inicial a fachada deveria ser revestida de tijolos cerâmicos, no entanto, após a revisão do projeto, foi decidido que a partir do $2^{\circ}$ pavimento as fachadas seriam revestidas com argamassa (emboço e reboco), tendo o reboco acabamento tipo massa raspada. O perímetro térreo, que deveria ser em granito natural, por medidas de economia, foi substituído por revestimento de argamassa (emboço e reboco) com acabamento tipo massa picolada.

Nota-se nesse relatório significativa preocupação com o custo da obra. As menções em relação às especificações de materiais e serviços apresentadas estão vinculadas, em sua maioria, a algum aspecto econômico. No entanto, o 
embasamento técnico das decisões demonstra-se pela pequena incidência de anomalias.

O projetista teve o cuidado de especificar argamassas mais resistentes para as paredes do pavimento térreo, que estão mais sujeitas às ações da água junto ao chão, e também a danos provocados pelos usuários (lascamentos de quinas, riscos, etc).

Ressalta-se ainda que o sistema de vedação vertical, constituído por parede de alvenaria de tijolos comuns (parede de um tijolo) e revestimento de argamassa em duas camadas, emboço com espessura da ordem de $20 \mathrm{~mm}$ e reboco com espessura da ordem de $8 \mathrm{~mm}$, atendem plenamente às exigências relativas à estanqueidade, uma vez que não existem problemas de infiltração de água.

O revestimento de modo geral está em bom estado de conservação. A maioria das fachadas está com bom aspecto quando observadas em seu todo. Este é o caso da fachada principal (Figura 1B).

Contribuem para o bom desempenho do sistema de revestimento os tijolos e ladrilhos cerâmicos instalados nos peitoris, e na face superior das molduras horizontais e a platibanda, pois essas peças possuem desenho específico relacionado à sua função, ou seja, oferecer proteção ao revestimento de argamassa.

Foram aplicados dois tipos de reboco; a massa picolada do pavimento térreo, um pouco mais clara e acinzentada e com resistência mecânica superior à massa raspada aplicada no revestimento a partir do $1^{\circ}$ pavimento, cuja coloração é um pouco mais escura e amarronzada.

Nota-se com alguma freqüência a presença de "remendos" executados sem maiores cuidados quanto à argamassa empregada. São motivados por intervenções principalmente em instalações, onde não houve a preocupação de preservar a fachada, buscando alternativa para o seu posicionamento. 
Por se tratar de argamassas extraídas de uma edificação de valor histórico, e para atender os objetivos específicos propostos para caracterização das argamassas, foram utilizadas as técnicas relacionadas a seguir:

- análise petrográfica;

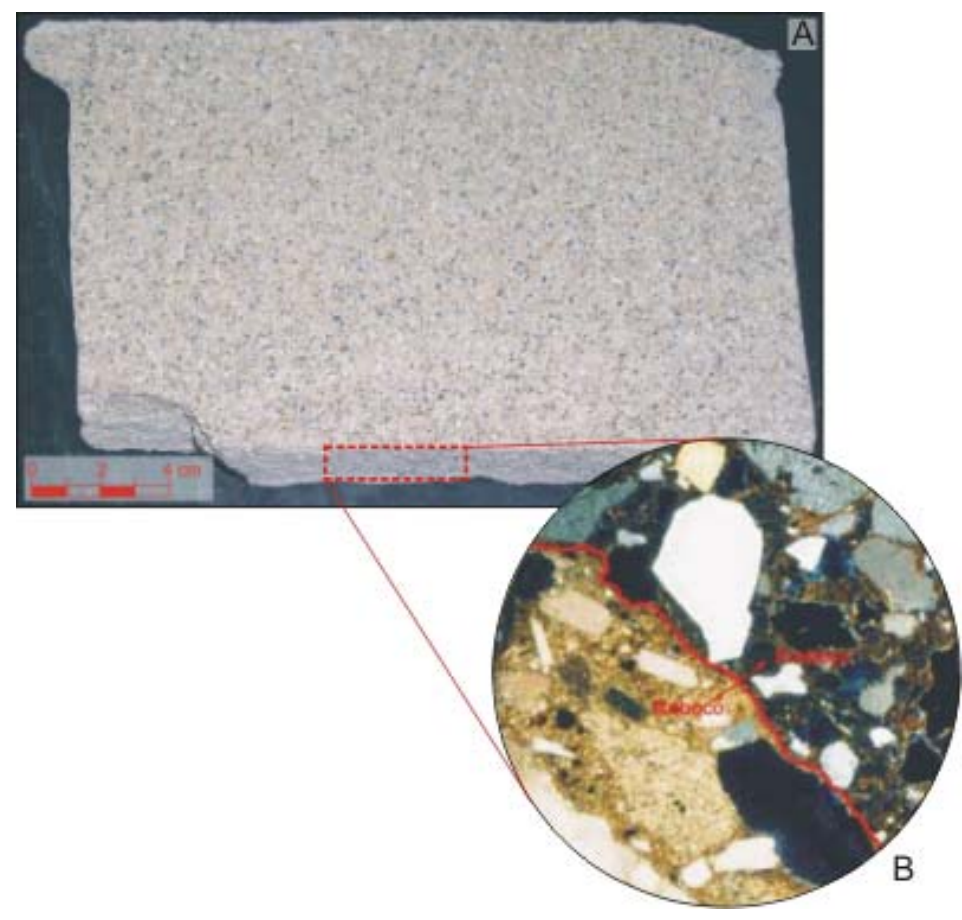

FIGURA 8 - (A) Amostra de revestimento L-T-J: Aspecto superficial da camada de reboco sem diferença de tonalidade em relação ao meio da camada. (Fotografia: Claudia B. do Nascimento).

(B) Mesma amostra, ao microscópio óptico. Contato do reboco com o emboço. No reboco predominam agregados carbonáticos (principalmente "filler") e baixa porosidade. No emboço predominam agregados de quartzo e a porosidade é mais alta. Notar a intensa carbonatação da pasta no reboco. Polarizadores cruzados. (Fotografia: Mírian C. B. de Oliveira).

- análise térmica diferencial e termogravimetria simultâneas;

- análise mineralógica por difratometria de raios $\mathrm{x}$;

- análise granulométrica por pipetagem e peneiramento e

- análise química.

Esta etapa consistiu em um estudo da argamassa, abrangendo a caracterização do agregado, dos vazios e da pasta, bem como definição das proporções entre os materiais. 
Com o objetivo de verificar a presença de microorganismos nos trechos do revestimento com coloração superficial diferente foi realizado exame de sanidade biológica de três amostras do revestimento.

Visando obter parâmetros físico-mecânicos para subsidiar a seleção de revestimentos para restauração das lacunas ou dos trechos deteriorados foram determinados:

- resistência à tração direta do sistema de revestimento de argamassa;

- absorção de água por capilaridade do sistema de revestimento de argamassa.

\subsection{Avaliação das condições de utilização da edificação em relação a suas instalações}

\subsubsection{Conforto ambiental}

O tema conforto ambiental foi abordado sob os aspectos térmico, lumínico e acústico, considerando o histórico das intervenções já realizadas na edificação.

Na época da construção do edifício, era prática corrente o uso de paredes externas e internas das edificações em alvenaria de tijolos maciços o que thes confere elevada inércia térmica, característica adequada às condições climáticas da cidade de São Paulo.

As grandes janelas existentes nos andares superiores, onde são realizadas atividades de escritório, foram concebidas visando maximizar o aproveitamento da luz natural e permitir, dada a sua grande altura, a renovação do ar por efeito chaminé, em seu próprio plano. Contudo, esta característica permite a entrada de grande quantidade de luz natural, que chega a ser excessiva nos dias de maior luminosidade do céu; reduz o isolamento sonoro da fachada bem como a inércia e a capacidade térmica das fachadas, além de permitir a entrada de carga térmica solar elevada.

Em reforma realizada no final da década de 1980, parte das paredes internas de alvenaria dos andares superiores foram substituídas por painéis leves de gesso, o 
que diminuiu a capacidade de armazenamento térmico da edificação e, assim, piorou as condições de conforto térmico. Naquela época, tentou-se remediar a situação reduzindo-se o ganho de calor pelas janelas com o emprego de filmes refletores nas janelas. Esta ação não se mostrou efetiva, pois os filmes instalados se destacaram dos vidros devido à dilatação térmica diferencial destes. Além disto, o emprego destes filmes altera a cor da luz que atravessa o envidraçamento, criando uma sensação psicológica desfavorável.

A redução da carga solar poderia ser feita com a instalação de elementos de sombreamento externos como Brises, porém esta ação descaracterizaria totalmente as fachadas. A instalação de cortinas internas, como foi feito, mostrou-se parcialmente satisfatória.

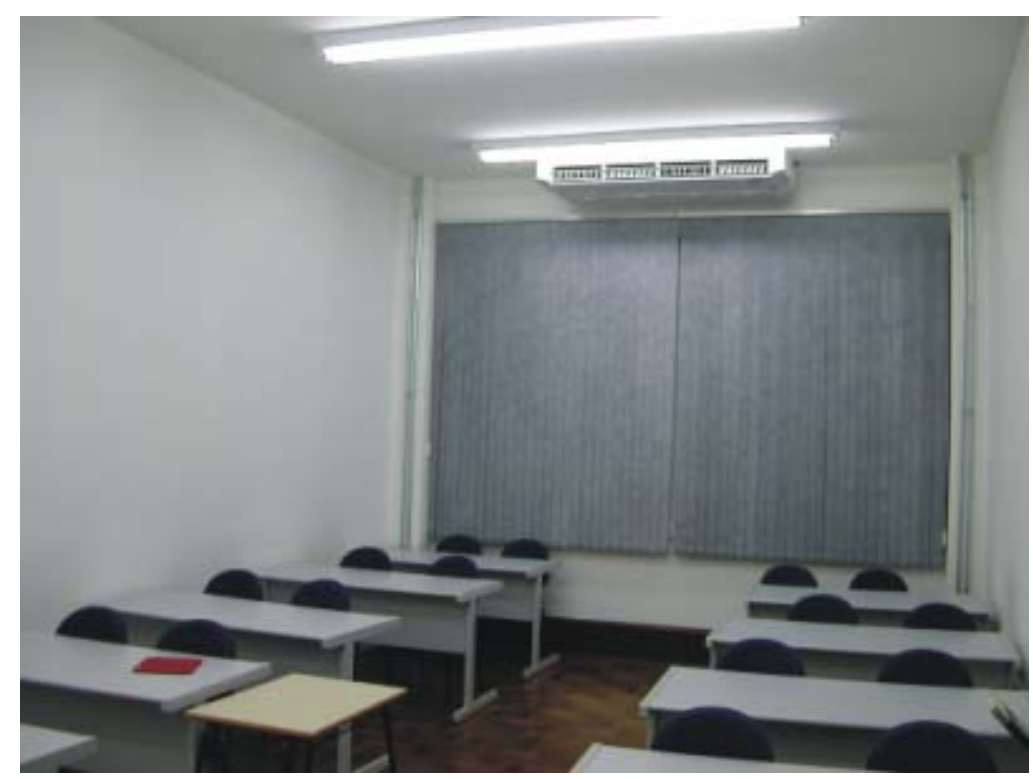

FIGURA 9 - Sala de aula com cortinas para redução da carga solar. É possível observar evaporadora de umidade minisplit instalada (Fotografia: Fulvio Vitorino).

A solução adotada foi a climatização dos ambientes com maior taxa de ocupação utilizando-se self-containeds com condensadores remotos resfriados a ar e distribuição de ar frio por dutos girovais aparentes, que foram pintados de amarelo claro, explicitando a sua condição de intervenção não original na edificação. Os condensadores foram instalados sobre um telhado, no fundo do edifício, fora da vista de quem observa o edifício do nível da rua.

Posteriormente, grande parte do edifício foi transformada em salas de aula de cursos de mestrado, com o emprego de paredes leves em painéis de gesso 
acartonado, e recebendo uma grande carga térmica interna devido à presença dos alunos. Esta situação impôs o uso de sistemas de climatização nas novas salas de aula. Foram utilizados sistemas mini-splits (Figura 9) pela facilidade de instalação, baixo nível de ruído interno, menor custo inicial e pelo menor grau de intervenção que estes equipamentos causam na edificação. Contudo, as unidades condensadoras foram fixadas à própria fachada descaracterizando-a parcialmente.

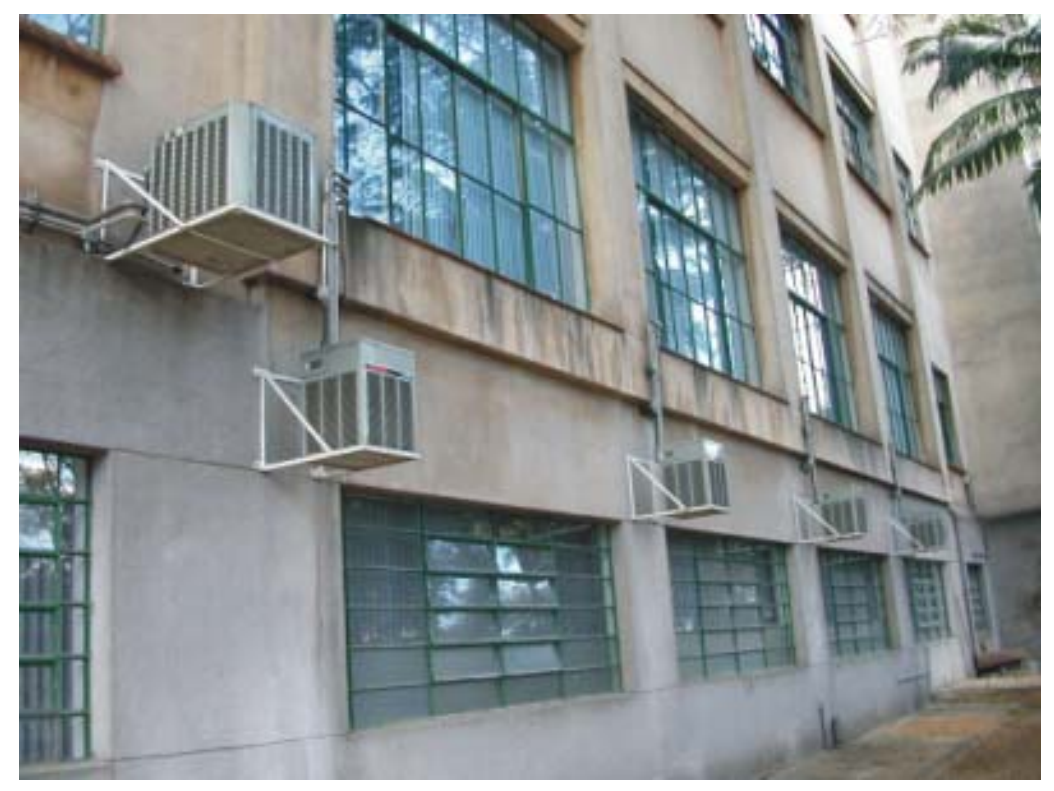

FIGURA 10 - Condensadoras dos mini-splits na fachada lateral do edifício. (Fotografia: Fulvio Vitorino).

Estas unidades poderiam ser instaladas distantes da edificação, sendo os tubos de condução de refrigerante disfarçados por "bonecas" em argamassa que causariam impacto visual muito menor.

Em termos de conforto acústico o edifício deve ser avaliado sob o enfoque do ruído proveniente do seu exterior e aquele gerado internamente. A proteção contra o ruído externo é feita pelas envoltórias (paredes e janelas). A grande espessura da parede propicia elevadíssimo isolamento acústico, devendo a atenção recair sobre as janelas. Dado o seu desgaste estes elementos apresentam frestas que permitem a passagem de ruído. Contudo, este fato não tem causado desconforto aos usuários da edificação, uma vez que o ruído externo não é elevado.

O nível de ruído interno também é baixo e, além disto, as soluções em painéis de gesso acartonado adotadas produzem isolamento sonoro compatível com os de alvenarias convencionais. 


\subsubsection{Segurança contra incêndios e planos de emergência}

Este trabalho foi efetuado por técnicos do IPT em parceria com a arquiteta Rosária Ono, do Departamento de Tecnologia da Arquitetura, da FAU - Faculdade de Arquitetura e Urbanismo da USP.

O edifício estudo-de-caso apresenta estrutura em concreto armado, resistente ao fogo. Parte das vedações é constituída de paredes em alvenaria de tijolos (sistema original) e parte, em chapas de gesso acartonado no sistema dry-wall. Os materiais e sistemas que compõem as vedações do edifício apresentam características que não contribuem para o desenvolvimento do incêndio, resultando em paredes que apresentam resistência ao fogo compatível com as dimensões dos compartimentos que as constituem.

As aberturas para ventilação e insolação (janelas), como acontece em grande parte dos edifícios antigos, são grandes e proporcionais ao pé-direito elevado dos pavimentos. Aberturas de grande altura favorecem, numa situação de incêndio, a ventilação e oxigenação do fogo, propiciando uma combustão intensa e rápida dos materiais combustíveis no interior do edifício. Exceção é feita ao piso térreo, constituído de pé-direito mais reduzido e, consequentemente, janelas de menor altura. As esquadrias das janelas são metálicas com painéis de vidro.

O edifício possui dois acessos de uso comum, sendo o principal localizado no $1^{\circ}$ pavimento, proporcionado por uma escadaria monumental que se inicia no logradouro público e o segundo, de serviço, por um portão na fachada posterior do edifício, no pavimento térreo. Existem, ainda, acessos independentes e de uso privativo dos laboratórios localizados no piso térreo. Para circulação vertical, existe uma única escada que liga do $1^{\circ}$ ao $3^{\circ}$ pavimentos e outra, no $1^{\circ}$ pavimento, que dá acesso somente ao piso térreo. Ambas as escadas são do tipo aberta, isto é, sem enclausuramento, apresentam estrutura resistente ao fogo e acabamento em material incombustível. A escada que liga os pavimentos superiores possui degraus regulares e patamar intermediário para circulação, apropriada para o movimento de abandono, enquanto que a escada que comunica o andar térreo ao $1^{\circ}$ pavimento apresenta parte dos degraus em leque e não tem patamar intermediário, sendo 
inadequada para uso coletivo no abandono do edifício. Dois elevadores realizam o transporte vertical entre todos os pavimentos.

As circulações horizontais para as salas e os laboratórios são realizadas através de corredores de largura generosa, separados dessas demais áreas por paredes de alvenaria ou gesso acartonado. As portas de acesso são de madeira, com exceção às portas de entrada do edifício, que são metálicas.

Em cerca de 1/3 da área de cobertura do edifício, existe uma separação entre a estrutura da cobertura, em madeira, e o ambiente do $3^{\circ}$ pavimento por lajes de concreto armado que apresentam pontos de descontinuidade. No restante da área, apenas o forro separa o ambiente do $3^{\circ}$ pavimento da estrutura da cobertura. Os materiais utilizados no forro do $3^{\circ}$ pavimento variam, sendo principalmente de estuque e placas de gesso, entre outros. Desta forma, existe um risco potencial de propagação do fogo iniciado no $3^{\circ}$ pavimento para a estrutura combustível da cobertura, pois o forro não apresenta características de resistência ao fogo.

O edifício apresenta revestimento externo das paredes em argamassa e parte significativa do revestimento interno em argamassa ou azulejo assentada sobre argamassa, que são materiais incombustíveis. Poucos materiais de revestimento e acabamento combustíveis, portanto, que podem gerar calor, gases quentes e nocivos, além de fumaça, contribuindo para o incêndio, foram encontrados nas paredes, como os painéis de lambril de madeira, no hall de entrada do $1^{\circ}$ pavimento. Os três pisos superiores apresentam acabamento de piso em tacos de madeira, que também são combustíveis, porém, se encontram numa posição desfavorável à propagação superficial do fogo, mais suscetivel para materiais instalados na vertical e no forro, devido à propriedade ascendente do calor e das chamas.

As instalações prediais elétricas e hidráulicas são dois aspectos que merecem destaque especial na avaliação de edifícios existentes, pois são fontes potenciais de risco de desastres como incêndios e infiltrações/inundações, respectivamente. Instalações elétricas antigas normalmente estão subdimensionadas e são compostas de materiais extremamente sensíveis ao calor, portanto, devem ser revisadas. As instalações hidráulicas se compõem de três sistemas distintos, a 
saber: suprimento de água, coleta de esgoto (água servida) e de águas pluviais. No caso de edifícios que abrigam acervos, a localização destas instalações devem ser consideradas de forma a evitar sua passagem nas áreas vulneráveis aos efeitos da água, pois podem ocorrer acidentes como vazamento ou rompimento das tubulações.

As instalações elétricas do edifício em estudo têm sido modernizadas, de forma que não apresentam riscos eminentes aos seus usuários, se adequando às atividades atuais, inclusive com o advento do ar-condicionado. As instalações hidráulicosanitárias do edifício estão situadas em zonas bem distintas e separadas das áreas de acervo, sendo que as tubulações não transpassam as áreas mais vulneráveis aos efeitos da água. As águas pluviais são coletadas por calhas na cobertura e descem por tubulações verticais no perímetro do edifício.

O edifício abriga várias atividades distintas, como guarda de acervo (biblioteca), laboratórios de ensaios, salas administrativas e infra-estrutura para atividades de ensino.

Dentre os riscos e vulnerabilidades detectados, diretamente relacionados às atividades exercidas podem ser destacados os seguintes:

- Guarda de acervo de importância histórica em papel que, ao mesmo tempo, representa uma grande quantidade de material combustível concentrada nos dois pisos superiores;

- Laboratórios que manipulam produtos químicos e inflamáveis no térreo;

- Grande concentração de pessoas que frequentam aulas, principalmente no período noturno, nas salas de aula do $1^{\circ}$ e $3^{\circ}$ piso, incompatível com a falta de alternativas de fuga.

\section{Conclusões e recomendações}

\subsection{Estrutura de concreto e alvenaria}

Está em bom estado de conservação, não apresentando problemas estruturais. 
No interior da edificação não foram constatadas quaisquer anomalias nos elementos estruturais ainda que a edificação abrigue grande parte do acervo da biblioteca do Instituto (carregamentos acentuados).

Recomendações:

- Tratamento dos trechos com corrosão de armadura;

- Vedação das juntas de dilatação entre os blocos com material elástico;

- Reparo das fissuras tomando os cuidados necessários para a restauração do revestimento da fachada;

- Substituição do forro do terceiro andar da ala central por sistema com menor risco de desabamento.

\subsection{Estruturas e elementos em madeira}

Madeiramento estrutural do Edifício encontra-se em bom estado de conservação. As estruturas em madeira da cobertura principal atendem aos requisitos de segurança exigidos por norma.

Recomendações:

- Controle de Fungos Apodrecedores;

- Controle de Cupins-subterrâneos;

- Controle do ataque com a realização de tratamento químico;

- Controle da infestação com a utilização de iscas.

\subsection{Revestimentos em placas de rocha}

Mármore rosa (revestimento do piso): desgastado. 
Não é relevante a restauração do piso, pois ações de repolimento ou consolidação tornará mais agudo o comprometimento estético.

Recomendações:

- Deve haver a limpeza do piso;

- Uso de tapetes apropriados;

- Limpeza diária com esfregões, a seco.

\subsection{Estruturas e elementos em metais}

Recuperação dos equipamentos e componentes inspecionados, por meio de pintura.

No caso da aquisição de elementos zincados, os revestimentos de zinco devem ser aplicados por imersão a quente.

\subsection{Revestimentos em Argamassas}

Medidas preventivas:

- Remoção de todas as partes em processo de destacamento para evitar acidentes;

- Recuperação das áreas do revestimento degradadas pela corrosão de armaduras.

Medidas curativas:

- Limpeza das fachadas;

- Recuperação das pingadeiras de proteção das molduras horizontais;

- Instalação de pingadeiras de proteção nas saliências do revestimento; 
- Recuperação das áreas degradadas com as formulações específicas a serem definidas para os dois tipos de reboco.

\subsection{Segurança contra incêndios e planos de emergência}

- Instalação de uma escada de emergência;

- Substituição do forro existente no $3^{\circ}$ pavimento por forro resistente ao fogo;

- Instalação de portas corta-fogo de folha dupla;

- Instalação de um sistema de extinção de incêndio por hidrantes e mangotinhos;

- Instalação de um sistema de detecção e alarme automáticos de incêndio;

- Aprimoramento do sistema de iluminação de emergência.

\section{Considerações finais}

Algumas recomendações feitas por ocasião da realização do projeto já foram colocadas em prática, tais como o controle de cupins subterrâneos e a recuperação de algumas áreas do revestimento degradadas pela corrosão de armaduras.

O prédio atualmente está mais uma vez mudando sua ocupação. A atual Diretoria do Instituto está com um projeto para sua revitalização. Acredita-se que o diagnóstico elaborado pelos pesquisadores do IPT, por meio da RETECOP seja útil nesse projeto de recuperação do Edifício Adriano Marchini.

\section{Equipe técnica}

Este trabalho foi realizado por equipe do IPT e da FAU-USP formada por pesquisadores de diversas áreas, apresentados a seguir: 


\section{Pesquisa histórica}

- Cristiane Alves de Souza - Historiadora

\section{Estrutura de concreto e alvenaria}

- Claudia Bastos do Nascimento - Engenheira Civil, Mestre em Engenharia

- Ivanísio de Lima Oliveira - Engenheiro Civil

\section{Estruturas e elementos em madeira}

- Gonzalo Antonio Carballeira Lopez - Biólogo, Mestre em Biologia

- Maria Beatriz Bacellar Monteiro - Bióloga, Mestre em Biologia

- Takashi Yojo - Engenheiro Civil, Doutor em Engenharia

\section{Revestimento em placas de rocha}

- Maria Heloísa Barros de Oliveira Frascá - Geóloga, Doutora em Ciências

\section{Estruturas e elementos em metais}

- Sidney Oswaldo Pagotto Júnior - Engenheiro de Materiais, Mestre em Engenharia

\section{Revestimento em argamassa}

- Gilberto De Ranieri Cavani - Engenheiro Civil, Mestre em Engenharia

- Fabiano Ferreira Chotoli - Químico, Mestre em Química

- Maria Beatriz Bacellar Monteiro - Bióloga, Mestre em Biologia

- Claudia Bastos do Nascimento - Engenheira Civil, Mestre em Engenharia

- Valdecir Angelo Quarcioni - Químico, Mestre em Química 
- Mirian Cruxên Barros de Oliveira - Geóloga, Doutora em Ciências

\section{Conforto ambiental}

- Maria Akutso - Física, Doutora em Física

- Fulvio Vitorino - Engenheiro Mecânico, Doutor em Engenharia

\section{Segurança ao fogo}

- Rosária Ono - Arquiteta, Doutora em Arquitetura

\section{Agradecimentos}

Os autores agradecem ao CNPq, pelo financiamento de parte do trabalho, e ao IPT, pela oportunidade que deu aos pesquisadores de realizar este trabalho num prédio do Instituto. Agradecem também à bolsista Marília Lopes, estudante de geologia, por executar a formatação deste artigo para publicação.

\section{Referências bibliográficas}

INSTITUTO DE PESQUISAS TECNOLÓGICAS. Avaliação da estrutura de concreto e da alvenaria de vedação do edifício Adriano Marchini. São Paulo: IPT, 2004. (IPT -Relatório Técnico № 72 311-205).

INSTITUTO DE PESQUISAS TECNOLÓGICAS. Exame de sanidade biológica e análise estrutural no madeiramento do edifício "Adriano Marchini"- Diagnóstico. São Paulo: IPT, 2004. (IPT - Relatório Técnico Nº 71 799).

INSTITUTO DE PESQUISAS TECNOLÓGICAS. Diagnóstico do estado de conservação do piso e escadaria do saguão de entrada do edifício Adriano Marchini. São Paulo: IPT, 2004. (IPT - Relatório Técnico No 71900 ).

INSTITUTO DE PESQUISAS TECNOLÓGICAS. Análise das estruturas e componentes metálicos instalados no edifício "Adriano Marchini” - Diagnóstico. São Paulo: IPT, 2004. (IPT - Relatório Técnico Nº 72 167).

INSTITUTO DE PESQUISAS TECNOLÓGICAS. Avaliação do revestimento das fachadas e caracterização de amostras de argamassa do edifício Adriano Marchini. São Paulo: IPT, 2005. (IPT - Relatório Técnico № $72246-$ 205).

OLIVEIRA, Mirian Cruxên Barros de. Rede de Apoio Tecnológico à Restauração e Conservação do Patrimônio Histórico - RETECOP. São Paulo: CNPq, 2004. (Relatório Resumido, № do Processo: 55.0136/2001-0). 


\section{Crédito}

* Geóloga, Doutora em Ciências - Instituto de Pesquisas Tecnológicas

e-mail: miriancr@ipt.br

${ }^{* *}$ Engenheiro Civil, Mestre em Engenharia - Instituto de Pesquisas Tecnológicas

e-mail: grcavani@ipt.br

O desenvolvimento desse trabalho teve apoio do Conselho Nacional de Desenvolvimento Científico e Tecnológico (CNPq). 